\title{
Self-assembled squalenoyl-cytarabine nanostructures as a potent nanomedicine for treatment of leukemic diseases
}

This article was published in the following Dove Press journal:

International Journal of Nanomedicine

22 May 2012

Number of times this article has been viewed

\author{
Donato Cosco' \\ Flavio Rocco ${ }^{2}$ \\ Maurizio Ceruti² \\ Margherita Vono' \\ Massimo Fresta ${ }^{1,3}$ \\ Donatella Paolino ${ }^{1,3}$ \\ 'Department of Health Sciences, \\ University "Magna Græcia”, \\ Catanzaro; ${ }^{2}$ Dipartimento di \\ Scienza e Tecnologia del Farmaco, \\ Torino; ${ }^{3}$ UOC Farmacia Ospedaliera \\ Fondazione per la Ricerca e la Cura \\ dei Tumori "Tommaso Campanella", \\ Campus Universitario "S Venuta", \\ Catanzaro, Italy
}

Background: In this investigation, the antileukemic activity of a new nanomedicine based on the conjugation of 1,1',2-tris-nor-squalenic acid with cytarabine (Ara-C) was evaluated.

Methods: Squalenoyl-Ara-C conjugate (Sq-Ara-C) self-assembled nanosystems were obtained by the nanoprecipitation method and characterized in vitro and in vivo.

Results: This new nanomedicine, which had a mean diameter of approximately $150 \mathrm{~nm}$, improved the in vitro antitumoral activity of Ara-C in different cancer cell lines (L1210, K562, and MCF-7). Sq-Ara-C nanomedicine allowed reduction of the $\mathrm{IC}_{50}$ value with respect to the free drug and was also active against drug-resistant leukemic cells (L1210R). A noticeable increase in the survival rate of mice with aggressive metastatic L1210R leukemia was observed after treatment with Sq-Ara-C (50 mg/kg) as compared with the free active compound ( $100 \mathrm{mg} / \mathrm{kg})$. Finally, evaluation of the biodistribution and pharmacokinetic profiles of the drug demonstrated that these nanoaggregates preferentially localized to the liver and spleen, and protected the drug from physiological metabolism.

Conclusion: Squalenoylation of cytarabine offers several pharmacological benefits both in vitro and in vivo.

Keywords: squalenoyl-cytarabine, self-assembly, antitumoral nanomedicine, leukemia, nanoaggregate, biodistribution

\section{Introduction}

Acute myeloid leukemia is a heterogeneous group of diseases characterized by uncontrolled proliferation of clonal neoplastic hematopoietic precursor cells and impaired production of normal hematopoiesis, leading to neutropenia, anemia, and thrombocytopenia. ${ }^{1}$ 1- $\beta$-D-arabinofuranosylcytosine (cytarabine, Ara-C) is standard therapy for acute and post-remission myeloid leukemia, especially in association with other active compounds, such as anthracyclines and etoposide..$^{2,3}$

Inside the cell, Ara-C is metabolized via the pathways normally utilized by natural nucleotide precursors. The metabolic step which limits the activation of Ara-C is its phosphorylation into Ara-CMP, which is carried out by deoxycytidine kinases. Ara-CMP is then activated by the pyrimidine, nucleoside monophosphate, and diphosphate kinases into Ara-CDP and Ara-CTP, respectively. Rapid deamination of Ara-C by cytidine deaminase catabolizes it into the nontoxic metabolite, Ara-U (1- $\beta$-D-arabinofuranosyluracil). ${ }^{4}$ Unfortunately, several mechanisms of cellular drug resistance have been described in patients with acute myeloid leukemia, in particular, the presence of transmembranic efflux pumps, such as P-glycoprotein, the difficulty of obtaining the triphosphorylated form of the drug inside cells, and deregulation of specific membrane nucleoside 
transporters (hENT1). All of these factors seem to influence the pharmacological efficacy of the active compound. ${ }^{5,6}$ Ara-C is also metabolized extracellularly by cytidine deaminase, leading to a short plasma half-life of 1.5 hours. $^{7}$

To overcome these limitations, a possible strategy could be drug encapsulation within a colloidal device in order to avoid destabilization phenomena. ${ }^{8-10}$ Our research team has used gemcitabine as a model compound with the aim of demonstrating the efficacy of liposomal and supramolecular carriers as drug delivery systems, showing improvement in the biopharmaceutical properties of the encapsulated molecules when compared with their free couterparts. ${ }^{11,12}$ Moreover, liposomal cytarabine (Depocyte ${ }^{\circledR}$ ) is also being used increasingly for the treatment and prophylaxis of central nervous system involvement in patients with leukemia/lymphoma. ${ }^{13-15}$

A new approach to improving the biopharmaceutical properties of the nucleoside analogs is their conjugation with the acyclic isoprenoid chain of squalene, a precursor in the biosynthesis of sterol. Squalene is widely distributed throughout nature, and is found particularly in olives, shark liver oil, wheat germ, and rice bran; it is also distributed ubiquitously in human tissues, particularly in the skin, and is well tolerated following intravenous injection and oral administration. ${ }^{16}$ It is very interesting to note that squalene inhibits proliferation of cancer cells by decreasing farnesyl pyrophosphate levels and does not influence normal biochemical pathways. ${ }^{17,18}$

The squalenoylation of some bioactive compounds allows nanostructures to self-assemble in an aqueous environment; these nanostructures are characterized by a hexagonal conformation in which the drug compound is surrounded by a shell. ${ }^{19}$ It has been observed that these nanoaggregates tend to improve the biopharmaceutical properties of compounds linked to squalenic acid, thus improving their antitumoral effects, prolonging the half-lives of antineoplastic drugs, and enhancing their interaction with biomembranes. ${ }^{20-23}$

In this investigation, a novel squalenoyl-Ara-C conjugate (Sq-Ara-C) was synthesized and prepared in the form of a nanomedicine, which was compared in vitro with the native drug in different cancer cell lines to confirm antitumoral activity. The Sq-Ara-C nanomedicine was also investigated in vivo with regard to its pharmacokinetic, biodistribution, and antileukemic characteristics in a mouse model.

\section{Materials and methods Materials}

Cytarabine (1- $\beta$-D-arabinofuranosylcytosine, Ara-C, purity $>99 \%$ ), dextrose, N-(fluorescein-5-tiocarbamoyl)- 1,2-dihexadecanoyl-sn-glycero-3-phosphoethanolamine triethylammonium salt (fluorescein-DHPE), phosphatebuffered saline solution, 3-[4,5-dimethylthiazol-2-yl]3,5-diphenyltetrazolium bromide salt (used for MTT testing), dimethylsulfoxide and amphotericin B solution $(250 \mu \mathrm{g} / \mathrm{mL}$ ) were purchased from Sigma-Aldrich (Milan, Italy). Squalene (purity $>99 \%$ ) was purchased from VWR (Milan, Italy). 1,1',2-tris-nor-squalene aldehyde was obtained from squalene using a method described previously. ${ }^{24}$ $\left[{ }^{3} \mathrm{H}\right]$ cholesteryl hexadecyl ether $\left(\left[{ }^{3} \mathrm{H}\right] \mathrm{CHE}, 40 \mathrm{Ci} / \mathrm{mmoL}\right)$ was obtained from Perkin Elmer-Italia (Monza, Italy). L1210 cells, K562 cells, and MCF-7 cells were provided by the Istituto Zooprofilattico of Modena and Reggio Emilia. RPMI 1640 medium with GlutaMAX ${ }^{\mathrm{TM}}$, Minimum Essential Medium with glutamine, trypsin/ethylenediamine tetra-acetic acid (EDTA) $1 \times$ solution, fetal bovine serum, and penicillinstreptomycin solution were obtained from Gibco (Invitrogen Corporation, Warrington, UK). Cytarabine was purchased from Sequoia Research (Pangbourne, UK). Pluronic F68 was provided by BASF (Cesano Maderno, Italy). All other materials and solvents used in this investigation were of analytical grade (Carlo Erba, Milan, Italy).

\section{Synthesis and characterization of Sq-Ara-C}

${ }^{1} \mathrm{H}$ nuclear magnetic resonance (NMR) spectra were recorded on a Bruker 300 ultrashield instrument (Karlsruhe, Germany) for samples in $\mathrm{CDCl}_{3}$ solution at room temperature, with $\mathrm{Me}_{4} \mathrm{Si}$ as the internal standard. Coupling constants $(J)$ are expressed in Hz. Mass spectra were recorded on a Finnigan MAT TSQ 700 spectrometer (San Jose, CA). The reactions were monitored by thin layer chromatography on precoated $\mathrm{F}_{254}$ silica gel sheets (Merck, Darmstadt, Germany); after being developed, the sheets were exposed to iodine vapor. Flash-column chromatography was performed on 230-400 mesh silica gel. Tetrahydrofuran was dried over sodium benzophenone ketyl. All solvents were distilled prior to flash chromatography.

The synthesis of 1,1',2-tris-nor-squalene acid (compound 2) is reported in Scheme 1. 1,1',2-tris-nor-squalene aldehyde 1 $(1.58 \mathrm{~g}, 4.12 \mathrm{mmol})$ was dissolved in $20 \mathrm{~mL}$ of diethyl ether at $0^{\circ} \mathrm{C}$. Sulfuric acid $(2.3 \mathrm{~mL})$ was separately added at $0^{\circ} \mathrm{C}$ to $20 \mathrm{~mL}$ of distilled water with stirring, followed by potassium dichromate (1.21 g, $4.12 \mathrm{mmol})$, to obtain chromic acid. It was then added to the solution of aldehyde 1 (which had been previously prepared) at $0^{\circ} \mathrm{C}$ over a period of 20 minutes, and left to react for 2 hours at $0^{\circ} \mathrm{C}$ with stirring. The reaction mixture was extracted with diethyl ether $(50 \mathrm{~mL} \times 3)$, washed 


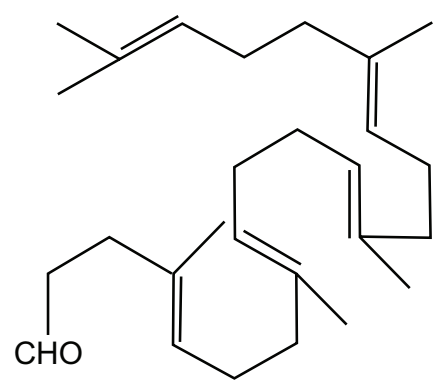

1

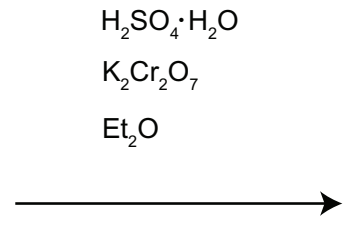

(l)

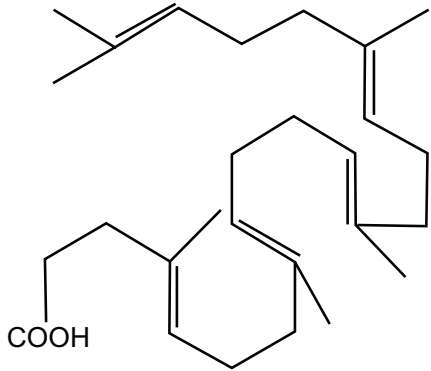

2
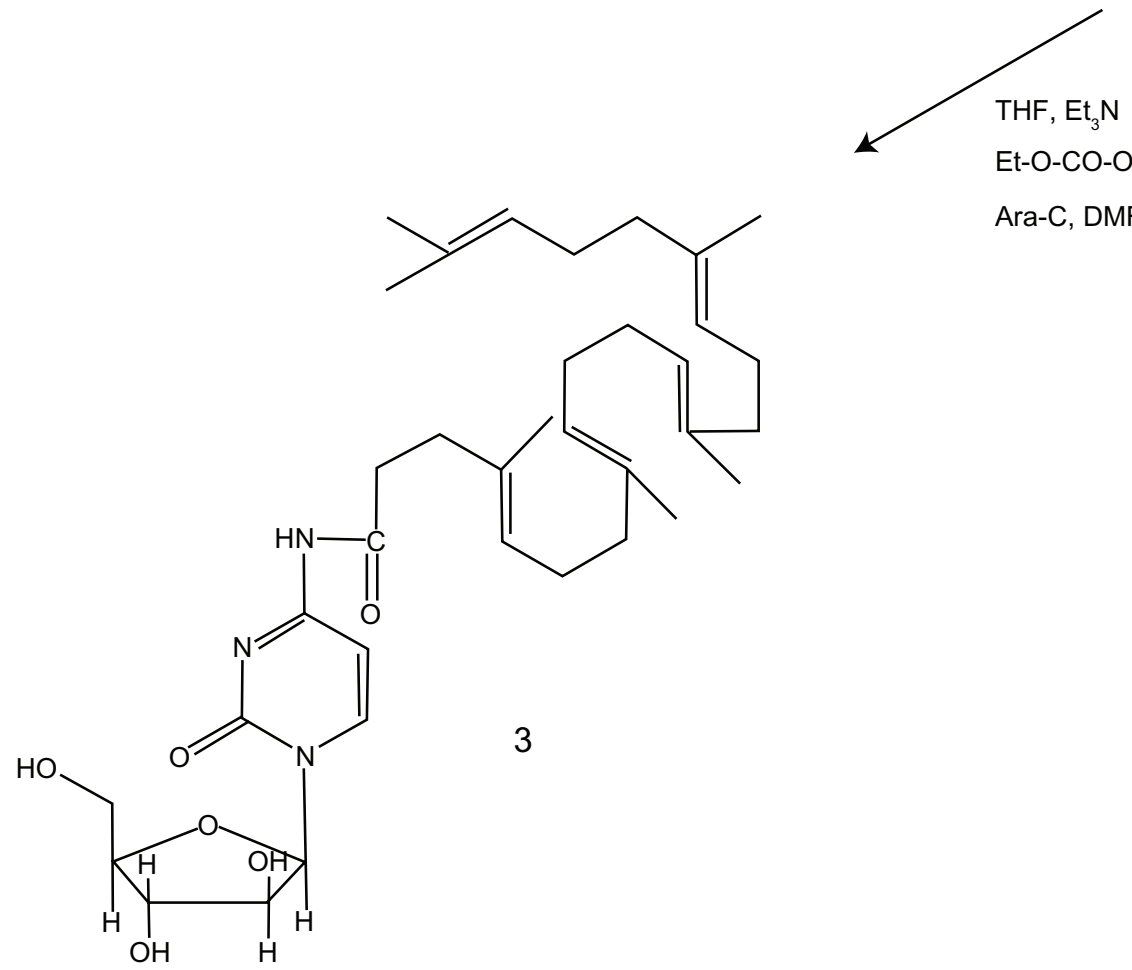

Ara-C, DMF

Scheme I Synthesis of 4-(N)-I,I',2-tris-nor-squalenoyl-cytarabine (Sq-Ara-C, compound 3) starting from I,I',2-tris-nor-squalene aldehyde (compound I), which was first oxidized into I, I',2-tris-nor-squalene acid (compound 2) and then conjugated with Ara-C.

with saturated brine, dried over anhydrous sodium sulfate, and evaporated in vacuo. Completion of the reaction was confirmed by silica gel thin layer chromatography, which was developed with light petroleum/diethyl ether/methanol (70:23:7 v/v/v). The crude product was purified by flash chromatography with light petroleum, then light petroleum/diethyl ether $(95: 5 \mathrm{v} / \mathrm{v})$ as the eluent, to yield $578 \mathrm{mg}$ of 1,1',2-tris-nor-squalene acid 2 (35\% yield), as a colorless oil. ${ }^{1} \mathrm{H}$ NMR $\left(\mathrm{CDCl}_{3}\right)$ : $\delta, 1.55-1.63$ (m, $18 \mathrm{H}$, allylic $\left.\mathrm{CH}_{3}\right), 1.90-2.05\left(\mathrm{~m}, 16 \mathrm{H}\right.$, allylic $\left.\mathrm{CH}_{2}\right)$, 2.26 (t, $2 \mathrm{H}, \mathrm{CH}_{2} \mathrm{CH}_{2} \mathrm{COOH}$ ), 2.38 (t, $2 \mathrm{H}, \mathrm{CH}_{2} \mathrm{CH}_{2} \mathrm{COOH}$ ), 5.00-5.19 (m, $5 \mathrm{H}$, vinylic $\mathrm{CH}$ ), 12.20 (broad, $1 \mathrm{H}, \mathrm{COOH}$ ). MS (EI): $m / z 400$ (M+ , 5), 357 (3), 331 (5), 289 (3), 208 (6), 136 (3), 81 (100).

The synthesis of $4-\left[(\mathrm{N})-1,1^{\prime}, 2\right.$-tris-nor-squalenoyl]-1 $\beta$ (arabinofuranosyl)-cytosine (Sq-Ara-C, compound 3) was carried out as reported in Scheme 1. Compound $2(338 \mathrm{mg}$, $0.845 \mathrm{mmol}$ ) was dissolved in $5 \mathrm{~mL}$ of anhydrous tetrahydrofuran in a three-necked flask under nitrogen with stirring, followed by addition of triethylamine $(85.5 \mathrm{mg}, 0.845 \mathrm{mmol})$ in $2 \mathrm{~mL}$ of anhydrous tetrahydrofuran, with cooling to $0^{\circ} \mathrm{C}$. Ethyl chloroformate $(91.7 \mathrm{mg}, 0.845 \mathrm{mmol})$ dissolved in $82 \mathrm{~mL}$ of anhydrous tetrahydrofuran was then added and left at $0^{\circ} \mathrm{C}$ for 20 minutes, with stirring, followed by addition of Ara-C (205.52 mg, $0.845 \mathrm{mmol})$ dissolved in $5 \mathrm{~mL}$ of warm anhydrous dimethylformamide, due to its scarce solubility. After reaching room temperature, the mixture was allowed to react for 3 days, with stirring under nitrogen. The reaction mixture was then controlled by silica gel thin layer chromatography, which was developed with light dichloromethane/ acetone $(95: 5 \mathrm{v} / \mathrm{v})$. The crude product was purified by 
flash chromatography with dichloromethane, then dichloromethane/acetone $(85: 15 \mathrm{v} / \mathrm{v})$, and finally dichloromethane/ acetone $(75: 25 \mathrm{v} / \mathrm{v})$ as mobile phases, to give $296 \mathrm{mg}$ of Sq-Ara-C (compound 3, scheme 1, 56\% yield), as a colorless, viscous oil. ${ }^{22} \mathrm{H}-\mathrm{NMR}\left(\mathrm{CD}_{3} \mathrm{COCD}_{3}\right): \delta, 1,55-1,68(18 \mathrm{H}, \mathrm{m}$, allylic $\left.\mathrm{CH}_{3}\right), 1,97-2,12\left(16 \mathrm{H}, \mathrm{m}\right.$, allylic $\left.\mathrm{CH}_{2}\right), 2,35(2 \mathrm{H}, \mathrm{t}$, $\left.\mathrm{NHCOCH}_{2} \mathrm{CH}_{2}\right), 2,64\left(2 \mathrm{H}, \mathrm{t}, \mathrm{NHCOCH}_{2}\right), 3,88(2 \mathrm{H}, \mathrm{m}$, $\left.5^{\prime}-\mathrm{CH}_{2}\right), 4,08$ (1 H, m, 4'-CH), 4,24-4,30 (2 H, m, 2'-CH and $\left.3^{\prime}-\mathrm{CH}\right), 4.65-5.00(3 \mathrm{H}$, broad peaks, $\mathrm{OH}), 5,02-5,25$ (5 H, m, vinylic $\mathrm{CH}), 6,189$ and $6.200(1 \mathrm{H}, \mathrm{d}, J=3.0 \mathrm{~Hz}$, $\left.1^{\prime}-\mathrm{CH}\right), 7,323$ and 7.349 ( $\left.1 \mathrm{H}, \mathrm{d}, J=9.0 \mathrm{~Hz}, 5-\mathrm{CH}\right), 8,187$ and $8.212(1 \mathrm{H}, \mathrm{d}, J=9.0 \mathrm{~Hz}, 6-\mathrm{CH}), 9.58-9.68$ ( $1 \mathrm{H}$, broad peak, NHCO). ${ }^{1} \mathrm{H}-\mathrm{NMR}$ (CD $\mathrm{CD}_{3}$ ): $\delta, 1,55-1,68$ (18 H, m, allylic $\left.\mathrm{CH}_{3}\right), 1,97-2,12\left(16 \mathrm{H}, \mathrm{m}\right.$, allylic $\left.\mathrm{CH}_{2}\right), 2,35(2 \mathrm{H}, \mathrm{t}$, $\left.\mathrm{NHCOCH}_{2} \mathrm{CH}_{2}\right), 2,54\left(2 \mathrm{H}, \mathrm{t}, \mathrm{NHCOCH}_{2}\right), 3,90(2 \mathrm{H}, \mathrm{m}$, $\left.5^{\prime}-\mathrm{CH}_{2}\right), 4,03$ (1 H, m, 4'-CH), 4,10 (1 H, m, 3'-CH), 4,250 (1 H, m, 2'-CH), 5,02-5,25 (5 H, m, vinylic $\mathrm{CH}), 6,192$ and $6.205\left(1 \mathrm{H}, \mathrm{d}, J=3.9 \mathrm{~Hz}, 1^{\prime}-\mathrm{CH}\right), 7,424$ and 7.449 (1 H, d, $J=7.5 \mathrm{~Hz}, 5-\mathrm{CH}), 8,230$ and $8.255(1 \mathrm{H}, \mathrm{d}, J=7.5 \mathrm{~Hz}$, 6-CH). MS (CI): $m / z 627\left(\mathrm{M}^{+}, 100\right), 609$ (65).

\section{Preparation and characterization of Sq-Ara-C nanoassemblies}

Sq-Ara-C nanoparticles were prepared using the nanoprecipitation method. Briefly, Sq-Ara-C was dissolved in acetone $10 \mathrm{mg} / \mathrm{mL}$ and added to an aqueous dextrose solution $(5 \% \mathrm{w} / \mathrm{v})$ drop by drop, under stirring at $500 \mathrm{rpm}$ in such a way as to promote self-assembly of the nanoparticles. The acetone used in this procedure was completely evaporated using a R210 rotary evaporator (Büchi-Italia, Milan, Italy), thus providing quantitative assembling of Sq-Ara-C. Pure squalene nanoparticles were obtained by nanoprecipitation of an ethanolic solution of squalene in an aqueous dextrose solution (5\% w/v) containing Pluronic F68 (1\% w/v).

The morphology of the Sq-Ara-C nanosystems was evaluated using a transmission electron microscope (Philips, Eindhoven, The Netherlands). Samples were analyzed at $100 \mathrm{kV}$. A drop of the sample was deposited on a copper screen coated with carbon. The sample was dried and then contrasted with uranyl acetate for 2 minutes and then washed with distilled water.

The mean size and polydispersity index of the Sq-Ara-C nanosystems were evaluated by dynamic light scattering. Dimensional analysis was carried out by photocorrelation spectroscopy (Nanosizer Nano ZS, Malvern Instruments Ltd, Worcestershire, UK) using a $4.5 \mathrm{~mW}$ laser operating at $670 \mathrm{~nm}$. Experiments were carried out at a back-scattering angle of $173^{\circ}$. Samples were suitably diluted with Milli-Q ${ }^{\circledR}$ water (Millipore Corporation, Billerica, MA) to avoid multiscattering phenomena and placed in a quartz cuvette. Experiments were carried out at room temperature. For each sample, 30 different measurements were performed.

Fluorescein-DHPE (0.1\% molar) was used to prepare fluorescent-labeled Sq-Ara-C nanosystems by dissolving the probe in the organic phase during the preparation process.

The Zetasizer Nano ZS was also used for zeta potential determination by applying a Smoluchowski constant F (Ka) of 1.5 to calculate the zeta potential value as a function of the electrophoretic mobility of the nanosystem. The various measurements were carried out in triplicate on three different batches (10 determinations for each batch). Results were expressed as the mean of three different experiments \pm standard deviation.

\section{Cell cultures}

L1210 (murine leukemia) and K562 (human chronic myelogenous leukemia) cells were incubated (Guaire ${ }^{\circledR}$ TS Autoflow Codue water-jacketed incubator) in plastic culture dishes $(100 \mathrm{~mm} \times 20 \mathrm{~mm})$ at $37^{\circ} \mathrm{C}\left(5 \% \mathrm{CO}_{2}\right)$ using RPMI 1640 medium with glutamate, penicillin $100 \mathrm{IU} / \mathrm{mL}$, streptomycin $100 \mu \mathrm{g} / \mathrm{mL}$, and fetal bovine serum $10 \% \mathrm{v} / \mathrm{v}$. The culture medium used for the MCF-7 (estrogen-responsive human breast cancer) cells was Minimum Essential Medium supplemented with glutamine, D-glucose, pyruvate, $10 \%(\mathrm{v} / \mathrm{v})$ fetal bovine serum, penicillin $100 \mathrm{IU} / \mathrm{mL}$, and streptomycin $100 \mu \mathrm{g} / \mathrm{mL}$. The medium was replaced with fresh medium every 48 hours. When about $80 \%$ confluence was reached, the cells were treated with trypsin (in the case of adherent cells) to separate them from the dishes and collected into a centrifuge tube containing $4 \mathrm{~mL}$ of the culture medium. The dishes were washed again with $2 \mathrm{~mL}$ of phosphate-buffered saline to remove the remaining cells, and then the phosphate-buffered saline was transferred into the centrifuge tube. The tube was centrifuged at $1000 \mathrm{rpm}$ and room temperature for 10 minutes using a Heraeus Sepatech Megafuge 1.0. The pellet was resuspended in an appropriate culture medium volume and seeded in culture dishes before investigation in vitro.

\section{Induction of resistance to Ara-C in LI 210 cells}

Resistance to Ara-C was induced by a graduated increase in drug concentration in the culture medium. The drug concentrations used were 0.001 (for 7 days), 0.05 (for 7 days), 0.25 (for 10 days), 0.50 (for 15 days), and $1.00 \mu \mathrm{M}$ (for 15 days), 
in that order. Cells were considered to be resistant to Ara-C (L1210R cells) when proliferation was undisturbed in the presence of a drug concentration of $1 \mu \mathrm{M}^{25}$

\section{Evaluation of in vitro cytotoxic activity}

The cytotoxic effects of Ara-C and the Sq-Ara-C nanomedicine were evaluated using the MTT test for cell viability. The cultured cells were plated in 96-well culture dishes $\left(5 \times 10^{3}\right.$ cells $/ 0.2 \mathrm{~mL}$ for MCF-7 cells and $8 \times 10^{3}$ cells $/ 0.2 \mathrm{~mL}$ for $\mathrm{K} 562$, L1210, and L1210R cells) and incubated for 24 hours at $37^{\circ} \mathrm{C}$ to promote their adhesion/settling onto the plate. The culture medium was then removed, replaced with the different formulations at different drug concentrations, and incubated for 24 and 48 hours. Each plate had eight wells containing untreated cells as the control and eight wells containing cells treated with pure squalenoyl nanosystems (without Ara-C) as the blank. After each incubation period, $10 \mu \mathrm{L}$ of tetrazolium salt solubilized in phosphatebuffered solution $(5 \mathrm{mg} / \mathrm{mL})$ were added to each well and the plates were then incubated again for 3 hours. After this period, the plates containing K562 and L1210 cells were centrifuged at $1500 \mathrm{rpm}$ for 5 minutes (ALC PK130) in order to obtain deposition of salts on the bottoms of the wells. The medium was removed and the formazan salts (precipitated on the well bottom after oxidation) were dissolved with $200 \mu \mathrm{L}$ of a mixture of dimethyl sulfoxide/ ethanol $(1: 1 \mathrm{v} / \mathrm{v})$ by shaking the plates for 20 minutes at $230 \mathrm{rpm}\left(\mathrm{IKA}^{\circledR} \mathrm{KS} 130\right.$ Control, IKA ${ }^{\circledR}$ Werke $\mathrm{GmbH}$ and Co, Staufen, Germany). The solubilized formazan was quantified using a microplate spectrophotometer (Multiskan MS 6.0, Labsystems, Kilsyth, Australia) at a wavelength of $540 \mathrm{~nm}$ with reference at a wavelength of $690 \mathrm{~nm}$. The percentage of cell viability was calculated according to the following equation:

$$
\text { Cell viability }(\%)=\mathrm{AbsT} / \mathrm{AbsC} \times 100
$$

where AbsT is the absorbance of treated cells and $\mathrm{AbsC}$ is the absorbance of control (untreated) cells. The formazan concentration is directly proportional to cell viability, which was reported as the mean of five different experiments \pm standard deviation.

\section{Interaction of Sq-Ara-C nanomedicine with cells}

The rate of interaction between the Sq-Ara-C nanomedicine and the different cell lines (L1210, L1210R, K562, and MCF-7) as a function of time $(0.5,1,2,4,6$, and 12 hours) was investigated. $\left[{ }^{3} \mathrm{H}\right] \mathrm{CHE}-$ radiolabeled $(0.003 \% \mathrm{w} / \mathrm{w}$ corresponding to $3 \mathrm{nmol}$ of $\left.\left[{ }^{3} \mathrm{H}\right] \mathrm{CHE}\right)$ nanosystems were used. All nanosystems were centrifuged $(80,000 \times \mathrm{g}$ for 30 minutes at $4^{\circ} \mathrm{C}$ ) and resuspended in a suitable medium before each investigation in order to prevent interference related to the $\left[{ }^{3} \mathrm{H}\right] \mathrm{CHE}$ molecules that were not integrated into the nanoaggregates. In particular, cells were plated in six-well culture dishes $\left(5 \times 10^{5}\right.$ cells $\left./ \mathrm{mL}\right)$ and successively treated with $100 \mu \mathrm{L}$ of tritiated formulation. After different incubation times, the cells were centrifuged (1200 rpm at room temperature for 10 minutes) to eliminate the culture medium, washed twice with phosphate-buffered saline, transferred into polypropylene liquid scintillation vials $(20 \mathrm{~mL}$ size $)$ (Sigma-Aldrich Chemie, GmbH, Steinheim, Germany), and dissolved in $2 \mathrm{~mL}$ of a quaternary ammonium hydroxide solution (BTS-450, Beckman Instruments Inc, Fullerton, CA) under continuous shaking for one hour at $60^{\circ} \mathrm{C}$ using an incubator shaker (Innova 4300, New Brunswick Scientific, Edison, NJ). At the end of the incubation period, $7 \mathrm{~mL}$ of liquid scintillation cocktail (Ready Organic, Beckman Coulter Inc, Fullerton, CA) were added, the samples were vigorously mixed and analyzed using a Wallac Win Spectral 1414 liquid scintillation counter (PerkinElmer Life and Analytical Sciences Inc, Waltham, MA). A 1414 Win Spectral Wallac LCS software program was used for data analysis.

\section{Confocal laser scanning microscopy}

Interaction between breast cancer cells and the fluoresceinlabeled Sq-Ara-C nanomedicine was evaluated by confocal laser scanning microscopy studies. For these experiments, $4 \times 10^{5}$ cells $/ \mathrm{mL}$ were placed in six-well culture plates with culture medium, and a sterile glass slide was positioned onto each well. Plates were incubated for 24 hours and the cells were then treated with fluoresceinated nanosystems for different incubation times. After incubation, each well was washed three times with phosphate-buffered saline to remove excess Sq-Ara-C, and the cells were then fixed on sterile glass slides using $1 \mathrm{~mL}$ of ethanol solution $(70 \% \mathrm{v} / \mathrm{v})$. Each slide was washed three further times with phosphate-buffered saline, and $2 \mathrm{~mL}$ of phosphate-buffered saline was added to each well. Plates were stored at $4{ }^{\circ} \mathrm{C}$ up to the time of the confocal laser scanning microscopy analysis. Before analysis, cover slides were positioned over the glass slides using a glycerol solution $(70 \% \mathrm{v} / \mathrm{v})$ to remove any entrapped air, and they were then fixed with transparent glue. The analysis was carried out using a Leica TCS SP2 MP confocal laser scanning microscope at $\lambda_{\text {exc }}=496 \mathrm{~nm}$ and $\lambda_{\mathrm{em}}=519 \mathrm{~nm}$. Scan resolution up to $4096 \times 4096$ pixels with an $\mathrm{Ar} / \mathrm{Kr}$ laser beam of $75 \mathrm{~mW}$, equipped with a fluorescein analyzer filter, was used for the 
experimental investigations. Samples were recorded using a macrodeveloper software package having multidimensional series acquisition and direct-access digital control knobs. An immersion oil lens $100 \times$ was used.

\section{In vivo experiments}

The animal experiments were carried out in agreement with the principles and procedures outlined by the local ethics committee and in accordance with the European Communities Council Directive of November 24, 1986 (86/609/EEC). The animals were maintained under standard conditions of both temperature $\left(20^{\circ} \mathrm{C} \pm 2^{\circ} \mathrm{C}\right)$ and humidity $(65 \%)$ on a 12 -hour light/12-hour dark cycle (light on $8 \mathrm{am}$ ), with food and water ad libitum.

\section{In vivo antitumoral activity}

Four-week-old DBA/2 mice weighing about 20-25 g (Harlan, San Pietro al Natisone, Udine, Italy) were used for the study. L1210R cells were maintained in vitro and injected intravenously $\left(1 \times 10^{5}\right.$ cells $/ 100 \mu \mathrm{L}$ phosphate-buffered saline $)$ into the mice, to obtain an aggressive metastatic leukemia model. The mice were then divided into five groups of ten animals each and treated on days $4,8,12,16$, and 20 with the following formulations: saline solution $(\mathrm{NaCl} 0.9 \% \mathrm{w} / \mathrm{v})$ as a control, Ara-C 100 mg/kg, Sq-Ara-C nanomedicine $(50 \mathrm{mg} / \mathrm{kg}$ equivalent of Ara-C), pure squalene nanosystems (drug absent), and a physical mixture of squalene nanosystems and Ara-C $100 \mathrm{mg} / \mathrm{kg}$. The body weight, feeding behavior, and motor activity of the mice were used as indicators of general health.

\section{Biodistribution of Sq-Ara-C nanomedicine}

Biodistribution experiments were also carried out using DBA $/ 2$ mice. $\left[{ }^{3} \mathrm{H}\right] \mathrm{CHE}(0.003 \% \mathrm{w} / \mathrm{w}$ corresponding to $3 \mathrm{nmol}$ of $\left.\left[{ }^{3} \mathrm{H}\right] \mathrm{CHE}\right)$ radiolabeled nanosystems $(200 \mu \mathrm{L})$ were injected into the mice through the tail vein. ${ }^{26}$ At different times, mice (three per time point) were sacrificed by cervical dislocation, and their hearts, lungs, livers, spleens, kidneys, and blood were collected. The organs were transferred in their entirety into $20 \mathrm{~mL}$ polypropylene liquid scintillation vials and mixed with $2 \mathrm{~mL}$ of a quaternary ammonium hydroxide solution under continuous shaking for 4 hours at $60^{\circ} \mathrm{C}$ to allow complete dissolution. At the end of the incubation period, various samples were decolorized with $2 \mathrm{~mL}$ of $24 \%(\mathrm{v} / \mathrm{v}) \mathrm{H}_{2} \mathrm{O}_{2}$ at room temperature for 5 minutes, and $7 \mathrm{~mL}$ of liquid scintillation cocktail were added. These mixtures were mixed vigorously and analyzed as described above. The 1414 Win Spectral Wallac LCS software was used for data analysis. To eliminate the radioactivity contained in the various organ samples and emanating from the nanosystems contained in the vascular space and tissue parenchyma (including macrophages and capillary endothelial cells, $X_{\text {tissue }}$ ), a correction was made according to the following equation:

$$
X_{\text {tissue }}=X_{\text {organ }}-\left(V_{0} \times C_{(t)}\right)
$$

where, $X_{\text {organ }}$ represents levels of radioactivity recovered from the various organ samples; $V_{0}$ is the total volume of the vascular space and interstitial fluid, as determined by the radioactivity level in various whole organ samples divided by blood concentration 10 minutes after intravenous injection of $\left[{ }^{3} \mathrm{H}\right]$ CHE-radiolabeled Sq-Ara-C nanomedicine; $C_{(t)}$ is blood concentration at the indicated time. A further quenching correction factor was obtained by measuring the radioactivity of blank tissues from noninjected mice spiked with known amounts of $\left[{ }^{3} \mathrm{H}\right] \mathrm{CHE}(0.030 \mu \mathrm{Cu} / \mu \mathrm{mol}$ lipids $) .{ }^{27}$

\section{Pharmacokinetic experiments}

DBA/2 mice were also used for the pharmacokinetic studies. Ara-C or Sq-Ara-C nanomedicine $(1 \mathrm{mg} / \mathrm{kg})$ was injected $(100 \mu \mathrm{L})$ through the tail vein (groups of three animals per each time point). Blood samples ( $200 \mu \mathrm{L})$ were taken from the retro-orbital plexus and frozen. Immediately before analysis, the samples were defrosted and centrifuged $(14,300 \times \mathrm{g}$, 10 minutes) at room temperature, and $50 \mu \mathrm{L}$ of glacial acetic acid was then added to the plasma samples to decrease the hydrogen bonding between nucleosides and proteins. Acetonitrile $(1 \mathrm{~mL})$ of high-pressure liquid chromatography grade (HPLC) was added to the plasma samples, which were then vortex-mixed and centrifuged at $800 \times \mathrm{g}$ for 15 minutes at $4^{\circ} \mathrm{C}$. The supernatant was removed and collected in a glass tube, and $1 \mathrm{~mL}$ of acetonitrile was added to the pellet. Three cycles of vortex-mixing and centrifugation were carried out. Supernatants were combined, evaporated to dryness under a nitrogen flux at $42^{\circ} \mathrm{C}$ (thermostated water bath), and stored at $-20^{\circ} \mathrm{C}$. Before the HPLC analysis, the residue was resuspended in $1 \mathrm{~mL}$ of water/methanol (55:45 v/v 1, HPLC grade), incubated for 5 minutes at $37^{\circ} \mathrm{C}$, and then centrifuged at $12,000 \times \mathrm{g}$ for 10 minutes at $20^{\circ} \mathrm{C}$. The supernatant was removed, filtered through a $0.22 \mu \mathrm{M}$ pore size Anotop 10 syringe filter (Whatman, Springfield Mill, UK) and placed in $4 \mathrm{~mL}$ HPLC glass vials for analytical determination. Analysis was carried out using an HPLC system (Varian Inc, Palo Alto, CA) composed of a 200-2031 Metachem online degasser, a M210 binary pump, a ProStar 410 autosampler, a G1316A thermostated column compartment, and a $25 \mu \mathrm{L}$ 
CSL20 Cheminert sample loop injector. Data were acquired and processed with Galaxie ${ }^{\circledR}$ chromatography manager software (Varian Inc). Chromatographic separation was carried out at room temperature using a GraceSmart RP C18 column $(4.6 \times 250 \mathrm{~mm}, 5 \mu \mathrm{M}$ particle size, Alltech Grom $\mathrm{GmbH}$, Rottenburg-Hailfingen, Germany). The mobile phase was water $(\mathrm{pH} 4.5) /$ methanol $(55: 45 \mathrm{v} / \mathrm{v})$, pumped at a flow rate of $1 \mathrm{~mL}$ per minute. Ultraviolet detection was set at $260 \mathrm{~nm}$.

No interference coming from plasma components was observed for cytarabine and its HPLC metabolite (Ara-U) peaks. The chromatographic method provided suitable separation of the peaks of cytarabine and Ara- $\mathrm{U}$, which showed a retention time of 4.50 minutes and 6.0 minutes, respectively. Quantification of cytarabine was carried out using an external standard curve in the linear concentration range of $0.1 \mu \mathrm{g} / \mathrm{mL}$ to $20 \mu \mathrm{g} / \mathrm{mL}$. A standard $1 \mathrm{mg} / \mathrm{mL}$ solution of cytarabine was used for construction of the standard curve. Plasma amounts of drug were determined using the standard curve according to the following equation:

$$
\mathrm{AUC}=0.76182 x+0.1
$$

where $x$ is the drug concentration $(\mu \mathrm{g} / \mathrm{mL})$ and AUC is the area under the curve $(\mathrm{mAu} \times$ minutes $)$. Pharmacokinetic calculations were carried out using WinNonlin Professional, version 5.3 (Tharsight, Mountain View, CA). Plasma Ara-C levels were expressed as $\mu \mathrm{g} / \mathrm{mL}$. Experimental data are the mean of three different experiments.

\section{Statistical analysis}

All data are expressed as the mean \pm standard deviation. Differences between the various experimental points were evaluated using one-way analysis of variance followed by the Tukey-Kramer multiple comparison test with GrafPAD Software for Science (San Diego, CA).

\section{Results}

\section{Characterization of Sq-Ara-C nanoassemblies}

Dynamic light scattering and transmission electron microscopic analysis of the nanosystems showed a mean size of about $150 \mathrm{~nm}$, with a polydispersity index of approximately 0.1 (highly homogenous size distribution, Table 1, Figure 1A). Moreover, a surface charge of about $-25 \mathrm{mV}$ was obtained, confirming the results of previous investigations. ${ }^{20}$ These values represent ideal parameters able to assure ideal biopharmaceutical properties for the nanoaggregates; in fact, various studies have demonstrated that the mean size and surface
Table I Physicochemical parameters of squalenoyl nanoaggregates*

\begin{tabular}{llll}
\hline Samples & Size $(\mathbf{n m})$ & $\begin{array}{l}\text { Polydispersity } \\
\text { index }\end{array}$ & $\begin{array}{l}\text { Zeta } \\
\text { potential }\end{array}$ \\
\hline $\begin{array}{l}\text { Squalenoyl } \\
\text { nanoassemblies }\end{array}$ & $105.6 \pm 12.7$ & $0.08 \pm 0.019$ & $-24.8 \pm 5.6$ \\
$\begin{array}{l}\text { Sq-Ara-C } \\
\text { nanomedicine }\end{array}$ & $146.1 \pm 6.7$ & $0.09 \pm 0.015$ & $-26.5 \pm 3.1$ \\
\hline
\end{tabular}

Note: *Each value represents the average of three different experiments \pm standard deviation.

charge can influence biodistribution of a colloidal formulation after intravenous administration. In particular, a mean size of less than $200 \mathrm{~nm}$ allows a long circulation time. ${ }^{11}$

\section{Evaluation of cytotoxicity in vitro}

The antitumoral efficacy of the Ara-C and Sq-Ara-C nanomedicine was evaluated in the different cancer cell lines in order to investigate whether the colloidal formulation was able to improve the antitumoral activity of the nucleoside analog. In particular, we used a leukemic murine cell line (L1210) which is very responsive to Ara-C, a resistant analog line (L1210R), a human leukemia cell line (K562), and a human breast cancer cell line (MCF-7). Squalenoyl nanosystems containing no drug did not decrease cell viability at the same dosages as used for Sq-Ara-C. The Sq-Ara-C nanomedicine improved the antitumoral effect of the active compound in all the cell lines investigated. As shown in Table 2, after 24 hours of incubation, Sq-Ara-C allowed reduction of the drug dosage by approximately 2.0-fold in L1210 cells, about 1.5-fold in L1210R, cells and about 2.5-fold in K562 cells in comparison with Ara-C. It was very interesting to observe that squalenoylation enabled Ara-C to exert its cytotoxic effects even on the MCF-7 cell line, which is generally less responsive to chemotherapy. In fact, Sq-Ara-C nanomedicine reduced cell viability by $50 \%$ at a dose of about $55 \mu \mathrm{M}$ while Ara-C achieved the same reduction at a concentration greater than $100 \mu \mathrm{M}$. After 48 hours of incubation, the difference in $\mathrm{IC}_{50}$ between the two formulations became more evident in the different cancer cell lines. The Sq-Ara-C nanomedicine achieved a further reduction in $\mathrm{IC}_{50}$ of about 2.5-fold in L1210R cells and about 4.0-fold in K562 and MCF-7 cells with respect to Ara-C. The cytotoxic effect was similar only in the L1210 cells, probably as a consequence of their great sensitivity to the active compound.

\section{Interaction between Sq-Ara-C nanomedicine and cell lines}

The improved cytotoxic effect of Ara-C conjugated with squalenic acid encased in a nanosystem could be due to greater 


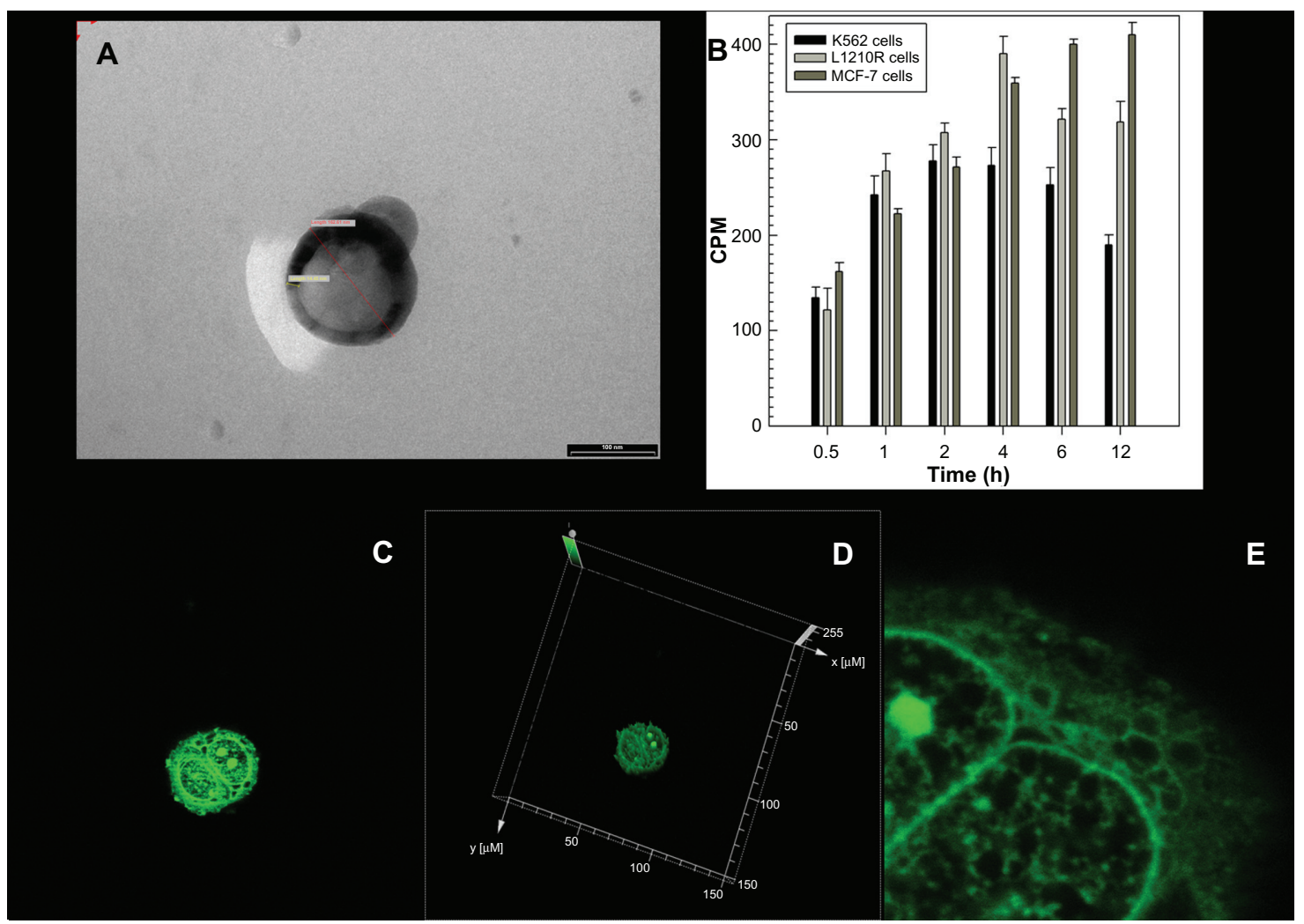

Figure I Transmission electron micrograph of the Sq-Ara-C nanoaggregates $(\mathbf{A})$. Interaction between $\left[{ }^{3} \mathrm{H}\right] \mathrm{CHE}$ radiolabeled Sq-Ara-C and the different cancer cell lines $(\mathbf{B})$. Confocal laser scanning micrograph (C), relative three-dimensional image (D) and $4 \times$ zoom (E) showing the interaction between MCF-7 cells and the fluorescein-DHPElabeled Sq-Ara-C nanoaggregates after 3 hours of incubation.

intracellular localization of the drug, so an investigation of the cell-nanosystem interaction using $\left[{ }^{3} \mathrm{H}\right] \mathrm{CHE}$-radiolabeled Sq-Ara-C nanomedicine was carried out. As shown in Figure 1B, after 4 hours of incubation, peak interaction between the Sq-Ara-C nanomedicine and the leukemic cell lines (K562, L1210, and L1210R) was reached, while the greatest intracellular colloidal accumulation in MCF-7 cells was reached after 12 hours (Figure 1B).

Data on the interaction between $\left[{ }^{3} \mathrm{H}\right] \mathrm{CHE}$-radiolabeled Sq-Ara-C nanomedicine and MCF-7 cells were in very good agreement with the findings of confocal laser scanning

Table 2 Evaluation of $\mathrm{IC}_{50}(\mu \mathrm{M})$ of Ara-C and Sq-Ara-C in different cancer cell lines*

\begin{tabular}{lccccc}
\hline & $2 \mathbf{2 4}$ hours & & & $\mathbf{4 8}$ hours & \\
\cline { 2 - 3 } \cline { 5 - 6 } \cline { 5 - 6 } & Ara-C & Sq-Ara-C & & Ara-C & Sq-Ara-C \\
\hline LI210 & $0.051 \pm 0.012$ & $0.027 \pm 0.008$ & & $0.022 \pm 0.003$ & $0.017 \pm 0.006$ \\
LI210R & $71.7 \pm 3.8$ & $44.6 \pm 2.6$ & & $48.2 \pm 5.3$ & $19.0 \pm 4.9$ \\
K562 & $55.9 \pm 4.9$ & $21.8 \pm 6.0$ & & $19.6 \pm 2.3$ & $4.2 \pm 1.5$ \\
MCF-7 & $>100$ & $56.3 \pm 5.8$ & $>100$ & $28.0 \pm 2.9$ \\
\hline
\end{tabular}

Note: *Each value represents the average of five different experiments \pm standard deviation. microscopy. Namely, after only 3 hours of incubation, the fluorescein-labeled Sq-Ara-C nanomedicine interacted strongly with the MCF-7 cells, giving them a characteristic green color (Figure 1C-E). It is interesting to note the presence of fluorescent spots on the cell membrane (Figure 1D), probably as a consequence of colloidal adsorption/fusion with the cells. ${ }^{28}$

\section{In vivo antileukemic activity of Sq-Ara-C nanomedicine}

The in vivo anticancer activity of the Sq-Ara-C nanomedicine $(50 \mathrm{mg} / \mathrm{kg})$ with respect to a simple solution of Ara-C at a 2.0fold higher drug dosage was evaluated in L1210R leukemiabearing mice. A colloidal formulation of pure squalenoyl nanosystems was used as the blank. Weight loss, dehydration, and limb paralysis were considered characteristic symptoms of leukemic pathology. The untreated control mice and animals treated with the blank developed these symptoms 6 days after injection of leukemic cells. Treating the mice with the different drug formulations caused delayed appearance of the aforementioned symptoms (Table 3).

As mentioned, weight loss is a clear sign of leukemia and is related directly to the severity of the disease, ie, the greater 
Table 3 Evaluation of physiological parameters in mice treated with the different formulations

\begin{tabular}{|c|c|c|c|}
\hline Samples & $\begin{array}{l}\text { Elapsed } \\
\text { time' (days) }\end{array}$ & $\begin{array}{l}\text { Mean weight } \\
\operatorname{loss}^{2}(\mathrm{~g})\end{array}$ & $\begin{array}{l}50 \% \text { survival }^{3} \\
\text { (days) }\end{array}$ \\
\hline Control & 6 & $\sim 3.2$ & 24 \\
\hline Pure Sq-Na & 6 & $\sim 2.6$ & 22 \\
\hline Ara-C (100 mg/kg) & 14 & $\sim 1.4$ & 38 \\
\hline Physical mixture & 15 & $\sim 1.0$ & 39 \\
\hline \multicolumn{4}{|l|}{ Ara-C/pure Sq-Na } \\
\hline Sq-Ara-C (50 mg/kg) & 46 & $\sim 0.4$ & 70 \\
\hline
\end{tabular}

Note: 'Time of appearance of symptoms of leukemia; ${ }^{2}$ weight loss in mice not inoculated with LI 2 IOR cells; ${ }^{3}$ days elapsed resulting in death of $50 \%$ of mice.

the weight loss the more severe the leukemic pathology. Treatment of mice with the various Ara-C formulations resulted in a weight reduction with respect to the untreated animals in the following decreasing order: Sq-Ara-C nanomedicine $50 \mathrm{mg} / \mathrm{kg}>$ Ara-C $100 \mathrm{mg} / \mathrm{kg}$ and a physical mixture of Ara-C/squalenoyl nanosystems $>$ squalenoyl nanosystems. The increased antileukemic effectiveness of the Sq-Ara-C nanomedicine was confirmed further by evaluating survival of leukemic-bearing mice as a function of time. As shown by the data on the survival rates for mice treated with the different formulations reported in Figure 2, the control group showed the same survival profile as mice treated with the squalenoyl nanosystems, while the Sq-Ara-C nanomedicine provided the greatest antileukemic effect. The Ara-C and the physical mixture of Ara-C/squalenoyl nanosystems induced the same variation in percentage of mouse

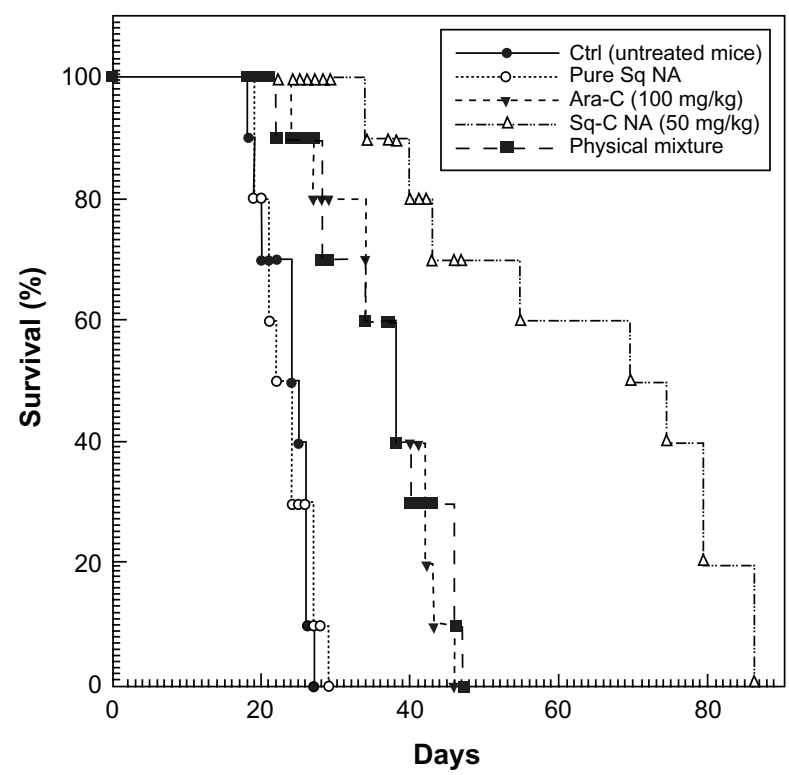

Figure 2 Survival profile of mice inoculated intravenously with $\mathrm{I} \times 10^{5} \mathrm{LI} 2 \mathrm{IOR}$ cells and treated with the different formulations. survival, demonstrating that the active compound has to be covalently linked to squalenic acid in order to improve its antileukemic efficacy.

\section{Biodistribution and pharmacokinetic profile of Sq-Ara-C nanomedicine}

Evaluation of the biodistribution profile of the $\left[{ }^{3} \mathrm{H}\right] \mathrm{CHE}$ radiolabeled Sq-Ara-C nanomedicine showed localization of the nanosystems in various organs following intravenous administration to DBA/2 mice. As shown in Figure 3, after one hour, many of the nanosystems were localized in the spleen, liver, and lungs as a consequence of uptake by macrophages in the reticuloendothelial system, while the colloids concentrated to a lesser degree in other organs. After the same period of time, a large amount of the administered dose was detected in the bloodstream. Localization of $\left[{ }^{3} \mathrm{H}\right] \mathrm{CHE}-$ radiolabeled Sq-Ara-C nanomedicine in the organs of the reticuloendothelial system was progressive, and after 24 hours was found to be particularly concentrated in the spleen, while the amount present in the bloodstream was substantially reduced. On the other hand, the presence of about $8 \%$ of the injected dose in the blood compartment indicated that conjugation of the active compound with a squalenic acid chain could be the cause of the increase in plasma half-life of the nucleoside analog after 24 hours, thus augmenting its antitumoral efficacy. Moreover, no appreciable difference (data not reported) in the biodistribution profiles was observed between the Sq-Ara-C nanomedicine and the squalenoyl nanosystems, showing that biodistribution was

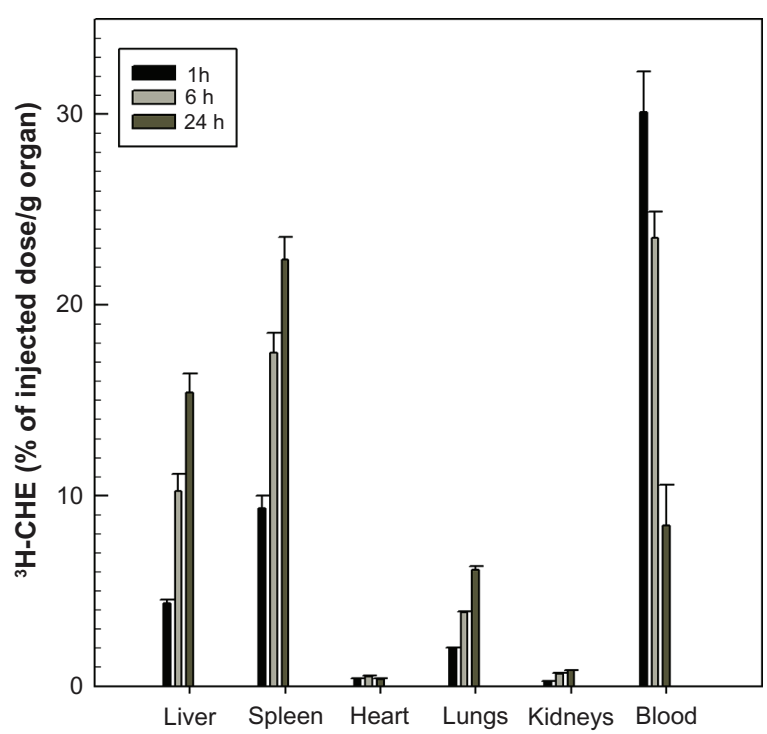

Figure 3 Biodistribution of $\left[{ }^{3} \mathrm{H}\right] \mathrm{CHE}$ radiolabeled Sq-Ara-C nanoaggregates in $\mathrm{DBA} / 2$ mice as a function of time. 
influenced mostly by the characteristics of the nanoparticles rather than those of the conjugated drug.

Evidence of the protective role played by the squalenic chain in the plasma metabolism of Sq-Ara-C and its improved biopharmaceutical features was determined by evaluating the pharmacokinetic profile of the Sq-Ara-C nanomedicine with respect to the Ara-C solution after intravenous administration. The Sq-Ara-C nanomedicine extended the drug half-life in plasma, which increased surprisingly by 6.0 -fold in comparison with the native Ara-C (Figure 4). Moreover, free Ara-C was completely undetectable 12 hours after administration, while quantification of the active compound was possible in the nanomedicine even after 24 hours.

These results are in agreement with those obtained by Couvreur et al who incubated squalenoyl-gemcitabine in human plasma for 24 hours, obtaining $80 \%$ of unmodified product with respect to free drug, and are also consistent with the findings of Reddy et al who investigated the pharmacokinetic profile of the same compound in mice. ${ }^{20,29}$

\section{Discussion}

Cytarabine is a hydrophilic molecule used widely in the treatment of leukemia. Unfortunately, numerous mechanisms of cellular resistance complicate the pharmacological efficacy of cytarabine. ${ }^{30}$ To overcome this problem, we have developed a new nanomedicine able to improve the antitumoral effects of cytarabine by conjugating it with squalenic acid, forming an amide linkage, which was done in order to obtain

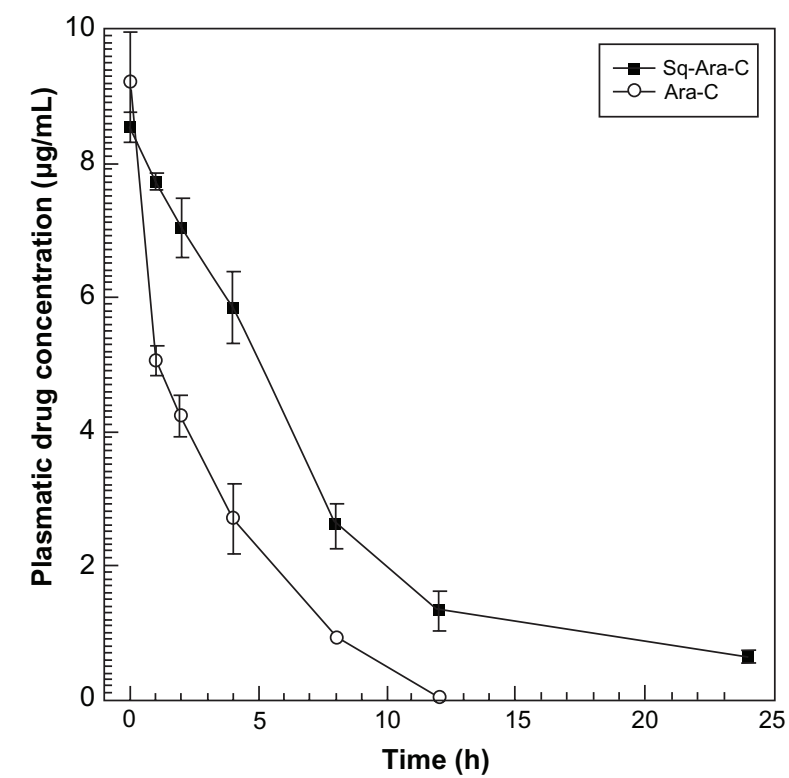

Figure 4 Pharmacokinetic profiles for free Ara-C and Sq-Ara-C in DBA/2 mice following intravenous administration of a $1 \mathrm{mg} / \mathrm{kg}$ dose.

Note: Data are the mean of three independent experiments \pm standard deviation. innovative nanosystems with a mean size of about $150 \mathrm{~nm}$. The nanoaggregates were observed to enable suppression of resistance of L1210R cells (which possess a downregulated $\mathrm{dCK}$ gene $)^{25}$ to the drug compound. In addition, the nanoaggregates favored a decrease in the $\mathrm{IC}_{50}$ of wild-type $\mathrm{L} 1210$ and K562 cells. A possible explanation is related to the deamination process necessary to degrade nucleosides. In the case of nanoaggregates, the presence of the amide linkage makes the colloids resistant to the enzymatic action of intracellular deaminases. It has also been shown that leukemic cells are rich in cathepsin B (a cysteine protease), which induces rapid cleavage of the Sq-Ara-C nanomedicine, releasing the active compound and allowing it to exert its antitumoral activity. ${ }^{31} \mathrm{It}$ is interesting to note that the nanoaggregates had a stronger cytotoxic effect with respect to the free form, although the breast cancer cell line was less responsive to cytarabine than were the other experimental cell lines, which caused accumulation of a greater amount of the nanomedicine.

It is probable that the improved in vitro anticancer effect of the Sq-Ara-C nanomedicine with respect to Ara-C is related to: resistance of the nanoaggregates to the action of intracellular deaminases; the large concentration of cathepsin B inside the tumoral cells; and the capacity of the active compound to penetrate tumor cells without the help of membrane nucleoside transporters, although the exact mechanism for this is not fully understood and is currently under investigation. ${ }^{28,32}$

The in vivo leukemic model confirmed our in vitro results, showing that the Sq-Ara-C nanomedicine achieves a better survival rate in treated mice than in those treated only with Ara-C. This finding is consistent with the results obtained with squalenoyl-gemcitabine in a leukemic murine model, validating the efficacy of squalenoylation as an innovative approach to the synthesis of nanomedicines..$^{20,33}$ In addition, it was interesting to note that $\left[{ }^{3} \mathrm{H}\right] \mathrm{CHE}-$ radiolabeled Sq-Ara-C nanomedicine concentrated in the liver and spleen, which, apart from bone marrow, are the major organs involved in metastatic lymphocytic leukemia. ${ }^{34}$ This trend was due to the phagocytic action of the reticuloendothelial system, which is able to recognize colloids. However, uptake of SqAra-C nanomedicine by the reticuloendothelial system was gradual, as seen in the pharmacokinetic data, which meant that Sq-Ara-C nanomedicine was detectable in the bloodstream for more than 24 hours following administration. Although the circulatory system is rich in deaminases other than just cytidine deaminase, it was demonstrated that squalene could interact with very low-density lipoproteins, thereby delaying deamination of the active compound. ${ }^{29,35}$ 


\section{Conclusion}

Squalenoylation represents a novel synthetic approach which is able to modulate the biopharmaceutical properties of bioactive compounds. The results obtained by Couvreur et al for the nucleoside analog, gemcitabine, and those reported here for Ara-C, led us to question whether this technological approach was really a valid starting point in the development of novel nanomedicines to be used in clinical practice. Although the advantages for the drug are irrefutable, it is the opinion of the authors that the clinical application of squalenoyl nanomedicine is not foreseeable in the near future, due to the fact that when a completely new compound is synthesized, a long road of regulatory procedures has to be embarked on to obtain approval for clinical use. However, further technological advancements ie, long circulation times and/ or selective targeting features, will enable the development of novel squalenoyl-based nanomedicines, the importance of which is hardly negligible in anticancer therapy.

\section{Acknowledgments}

The authors thank the Italian Ministry of Research and the Regione Piemonte for financial support. This manuscript was supported by The Italian Association for Cancer Research Special Program in Molecular Clinical Oncology (9980, 2010-15). The authors are very grateful to Lynn Whitted for revision of the manuscript, and thank Cristina Salvatici for the transmission electron microscopic analysis.

\section{Disclosure}

The authors report no conflicts of interest in this work.

\section{References}

1. Tallman MS, Gilliland DG, Rowe JM. Drug therapy for acute myeloid leukemia. Blood. 2005;106(4):1154-1163.

2. Tsurumi H, Kanemura N, Hara T, et al. Therapeutic strategy of untreated de novo acute myeloid leukemia in the elderly: the efficacy of continuous drip infusion with low dose cytarabine and etoposide. J Cancer Res Clin Oncol. 2007;133(8):547-553.

3. Robak T, Wierzbowska A. Current and emerging therapies for acute myeloid leukemia. Clin Ther. 2009;31(Pt 2):2349-2370.

4. Galmarini CM, Thomas X, Calvo F, et al. Potential mechanisms of resistance to cytarabine in AML patients. Leuk Res. 2002;26(7):621-629.

5. Boleti H, Coe IR, Baldwin SA, Young JD, Cass CE. Molecular identification of the equilibrative NBMPR-sensitive (es) nucleoside transporter and demonstration of an equilibrative NBMPR-insensitive (ei) transport activity in human erythroleukemia (K562) cells. Neuropharmacology. 1997;36(9):1167-1179.

6. Michieli M, Damiani D, Ermacora A, et al. P-glycoprotein, lung resistance-related protein and multidrug resistance associated protein in de novo acute non-lymphocytic leukaemias: biological and clinical implications. Br J Haematol. 1999;104(2):328-335.

7. Hamada A, Kawaguchi T, Nakano M. Clinical pharmacokinetics of cytarabine formulations. Clin Pharmacokinet. 2002;41(10): 705-718.
8. Celano M, Schenone S, Cosco D, et al. Cytotoxic effects of a novel pyrazolopyrimidine derivative entrapped in liposomes in anaplastic thyroid cancer cells in vitro and in xenograft tumors in vivo. Endocr Relat Cancer. 2008;15(2):499-510.

9. Paolino D, Cosco D, Licciardi M, Giammona G, Fresta M, Cavallaro G. Polyaspartylhydrazide copolymer-based supramolecular vesicular aggregates as delivery devices for anticancer drugs. Biomacromolecules. 2008;9(4):1117-1130.

10. Fontana G, Maniscalco L, Schillaci D, Cavallaro G, Giammona G. Solid lipid nanoparticles containing tamoxifen characterization and in vitro antitumoral activity. Drug Deliv. 2005;12(6):385-392.

11. Paolino D, Cosco D, Racanicchi L, et al. Gemcitabine-loaded PEGylated unilamellar liposomes vs Gemzar: biodistribution, pharmacokinetic features and in vivo antitumor activity. J Control Release. 2010;144(2):144-150.

12. Licciardi M, Paolino D, Celia C, Giammona G, Cavallaro G, Fresta M. Folate-targeted supramolecular vesicular aggregates based on polyaspartyl-hydrazide copolymers for the selective delivery of antitumoral drugs. Biomaterials. 2010;31(28):7340-7354.

13. Benesch M, Urban C. Liposomal cytarabine for leukemic and lymphomatous meningitis: recent developments. Expert Opin Pharmacother. 2008;9(2):301-309.

14. Parasole R, Menna G, Marra N, et al. Efficacy and safety of intrathecal liposomal cytarabine for the treatment of meningeal relapse in acute lymphoblastic leukemia: experience of two pediatric institutions. Leuk Lymphoma. 2008;49(8):1553-1559.

15. Benesch M, Siegler N, Hoff K, et al. Safety and toxicity of intrathecal liposomal cytarabine (Depocyte) in children and adolescents with recurrent or refractory brain tumors: a multi-institutional retrospective study. Anticancer Drugs. 2009;20(9):794-799.

16. Reddy LH, Couvreur P. Squalene: A natural triterpene for use in disease management and therapy. Adv Drug Deliv Rev. 2009;61(15): 1412-1426.

17. Newmark HL. Squalene, olive oil, and cancer risk: a review and hypothesis. Cancer Epidemiol Biomarkers Prev. 1997;6(12):1101-1103.

18. Smith TJ. Squalene: potential chemopreventive agent. Expert Opin Investig Drugs. 2000;9(8):1841-1848.

19. Couvreur P, Reddy LH, Mangenot S, et al. Discovery of new hexagonal supramolecular nanostructures formed by squalenoylation of an anticancer nucleoside analogue. Small. 2008;4(2):247-253.

20. Couvreur P, Stella B, Reddy LH, et al. Squalenoyl nanomedicines as potential therapeutics. Nano Lett. 2006;6(11):2544-2548.

21. Castelli F, Sarpietro MG, Ceruti M, Rocco F, Cattel L. Characterization of lipophilic gemcitabine prodrug-liposomal membrane interaction by differential scanning calorimetry. Mol Pharm. 2006;3(6): 737-744.

22. Sarpietro MG, Micieli D, Rocco F, Ceruti M, Castelli F. Conjugation of squalene to acyclovir improves the affinity for biomembrane models. Int J Pharm. 2009;382(1-2):73-79.

23. Voyron S, Rocco F, Ceruti M, et al. Antifungal activity of bisazasqualenes, inhibitors of oxidosqualene cyclase. Mycoses. 2010;53(6): $481-487$.

24. Ceruti M, Balliano G, Rocco F, et al. Synthesis and biological activity of new iodoacetamide derivatives on mutants of squalene-hopene cyclase. Lipids. 2005;40(7):729-735.

25. Bergman AM, Pinedo HM, Jongsma AP, et al. Decreased resistance to gemcitabine $\left(2^{\prime}, 2^{\prime}\right.$-difluorodeoxycitidine $)$ of cytosine arabinosideresistant myeloblastic murine and rat leukemia cell lines: role of altered activity and substrate specificity of deoxycytidine kinase. Biochem Pharmacol. 1999;57(4):397-406.

26. Mudhakir D, Akita H, Khalil IA, Futaki S, Harashima H. Pharmacokinetic analysis of the tissue distribution of octa-arginine modified liposomes in mice. Drug Metab Pharmacokinet. 2005;20(4):275-281.

27. Gabizon A, Price DC, Huberty J, Bresalier RS, Papahadjopoulos D. Effect of liposome composition and other factors on the targeting of liposomes to experimental tumors: biodistribution and imaging studies. Cancer Res. 1990;50(19):6371-6378. 
28. Bildstein L, Dubernet C, Marsaud V, et al. Transmembrane diffusion of gemcitabine by a nanoparticulate squalenoyl prodrug: an original drug delivery pathway. J Control Release. 2010;147(2):163-170.

29. Reddy LH, Khoury H, Paci A, et al. Squalenoylation favorably modifies the in vivo pharmacokinetics and biodistribution of gemcitabine in mice. Drug Metab Dispos. 2008;36(8):1570-1577.

30. Damaraju VL, Damaraju S, Young JD, et al. Nucleoside anticancer drugs: the role of nucleoside transporters in resistance to cancer chemotherapy. Oncogene. 2003;22(47):7524-7536.

31. Reddy LH, Dubernet C, Mouelhi SL, Marque PE, Desmaele D, Couvreur P. A new nanomedicine of gemcitabine displays enhanced anticancer activity in sensitive and resistant leukemia types. $J$ Control Release. 2007;124(1-2):20-27.
32. Reddy LH, Renoir JM, Marsaud V, Lepetre-Mouelhi S, Desmaële D, Couvreur P. Anticancer efficacy of squalenoyl gemcitabine nanomedicine on 60 human tumor cell panel and on experimental tumor. Mol Pharm. 2009;6(5):1526-1535.

33. Reddy LH, Marque PE, Dubernet C, Mouelhi SL, Desmaële D, Couvreur P. Preclinical toxicology (subacute and acute) and efficacy of a new squalenoyl gemcitabine anticancer nanomedicine. J Pharmacol Exp Ther. 2008;325(2):484-490.

34. Wanko SO, de Castro C. Hairy cell leukemia: an elusive but treatable disease. Oncologist. 2006;11(7):780-789.

35. Strandberg TE, Tilvis RS, Miettinen TA. Metabolic variables of cholesterol during squalene feeding in humans: comparison with cholestyramine treatment. J Lipid Res. 1990;31(9):1637-1643.
International Journal of Nanomedicine

\section{Publish your work in this journal}

The International Journal of Nanomedicine is an international, peerreviewed journal focusing on the application of nanotechnology in diagnostics, therapeutics, and drug delivery systems throughout the biomedical field. This journal is indexed on PubMed Central, MedLine, CAS, SciSearch ${ }^{\circledR}$, Current Contents ${ }^{\circledR} /$ Clinical Medicine,

\section{Dovepress}

Journal Citation Reports/Science Edition, EMBase, Scopus and the Elsevier Bibliographic databases. The manuscript management system is completely online and includes a very quick and fair peer-review system, which is all easy to use. Visit http://www.dovepress.com/ testimonials.php to read real quotes from published authors. 